To appear, Studies in History and Philosophy of Science

\title{
How physics flew the philosophers' nest
}

\author{
Katherine Brading \& Marius Stan
}

\section{Introduction}

Nowadays, physics and philosophy are housed in separate departments on university campuses. They are distinct disciplines with their own journals and conferences, and in general they are practiced by different people, using different tools and different methods. This was not always the case: up until the early I7th century (at least), physics was a part of philosophy. So, what happened? And, what philosophical lessons should we take away?

The standard story we tell ourselves is that this split took place during the I7th century. ${ }^{\mathrm{I}}$ As a vivid illustration, compare the fate of Descartes Principles of Philosophy with Newton's Mathematical Principles of Natural Philosophy, published less than 50 years apart, in I644 and I687, respectively. There is considerable overlap in the two projects, and Newton's book is helpfully read as responding in part to Descartes. Yet Descartes' Principles is taught today in philosophy departments, and we think of it as a text in the history of philosophy, whereas Newton's Principia is not taught as a canonical text in philosophy, and is claimed by physicists for the history of physics. One explanation might be this: some time between the two, the "Scientific Revolution" took place, yielding Newton's Principia as its crowning achievement. In the process, physics achieved autonomy from philosophy, leaving Descartes' Principles behind. Upshot: by the end of the I7th century, physics had flown the philosophers' nest, and the I8th century saw physicists doing Kuhnian "normal science" and solving puzzles within the Newtonian paradigm.

\footnotetext{
I The "standard story" as we rehearse it here has been challenged, revised, and rejected in various ways. See, for example, Pulte 1993 and Caparrini \& Fraser 2013. These authors are historians of physics. See also Shank 2008. We offer a new way of thinking about the philosophical reasons that played a role in the split that did, eventually, emerge.
} 
But this is not really how it happened. There is no doubt that important developments in natural philosophy took place in the I 7 th century, and that Newton's Principia was enormously influential for the evolving relationship between physics and philosophy. Nevertheless, as of the early i8th century, the split between physics and philosophy had not yet taken place. Here, for example, is leading natural philosopher Musschenbroek, ${ }^{2}$ writing in the 1720 and giving a nice taxonomy of philosophy in which physics is one part of philosophy (we quote here from the later English translation):

Philosophy is the knowledge of all things both divine and human, and of their properties, operations, causes, and effects; which may be known by the understanding, the senses, reason, or by any other way whatever...

Philosophy is a very ample science, and therefore ought to be divided into certain parts, which we shall reduce to the six following...

- Pneumatics "which comprehends whatever belongs to spiritual existences, their attributes and operations"

- Physicks "which considers the space of the whole universe, and all bodies contained in it; enquires into their nature, attributes, properties, actions, passions, situation, order, powers, causes, effects, modes, magnitudes, origins"

- Teleology "which investigates the ends, for the sake of which all things in the universe have their existence, and all their actions, changes and motions are performed"

- Metaphysics "which explains such general things as are in common to all created beings. As what is being, substance, mode, relation, possible, impossible, necessary, contingent, etc."

- Moral philosophy "gives us rules, by which we should direct all our actions"

- Logick "which considers the intelligent and reasoning faculty of the human mind, and instructs us in the methods of reasoning justly, and of avoiding error..." (Musschenbroek I744: I-2)

For our purposes, the most important things to note are the inclusion of physics within philosophy, and the characterization of physics as encompassing "the

\footnotetext{
${ }^{2}$ Musschenbroek was a highly renowned natural philosopher and experimentalist in the I8th century (see Ducheyne 2015), and is perhaps most famous now for his invention of the Leyden jar.
} 
space of the whole universe, and all bodies contained in it", including their nature, attributes, properties, powers, causes, etc. On this view, the primary subject-matter of physics is bodies, and the only features of bodies that do not fall within the purview of physics are those that belong to created beings in general, that is, to both bodily and spiritual beings; the study of these most general features belongs to metaphysics. As a result, many aspects of bodies that we might think of today as being the subject of metaphysics, such as the nature, powers, causes, effects and origins of bodies, fall within physics.

This conception of physics-or "natural philosophy," as it was also known - was widely held at the time, ${ }^{3}$ and provides some initial evidence that physics was not yet an autonomous discipline. More evidence will be given as we proceed. If we want to see the split between physics and philosophy unfold, and to understand the philosophical reasons for it, then we have to look not only before the Principia, but after it too.

Here is what we find. There is one particular problem, dating back to Descartes and persisting long into the 18 th century, that plays a pivotal role. The failure to solve it, despite repeated efforts, precipitates a profound change in the relationship between physics and philosophy. The culprit is the problem of collisions. Innocuous though it may seem, this problem becomes the bellwether of deeper issues concerning the nature and properties of bodies in general. Namely, the ultimate failure of attempts to combine a matter theory with rules of motion into a complete account of collisions is symptomatic of a much broader failure throughout the century: the inability to integrate a philosophical physics of body with a mathematized mechanics in ways that produced stable agreement. The failure to successfully address the problem led to a reconceptualization of the goals and subject-matter of physics, and to physics flying the philosophers' nest. Or so we shall argue.

\section{Some I7th century background}

Three episodes from the I 7 th century provide the necessary background for understanding why collisions became such a serious problem in the I8th century. The first is the place of collisions in Descartes's philosophy; the second is the investigations into rules of collision by the Royal Society of London in the I660s; and the third is Malebranche's theory of collisions from the late I6oos,

${ }^{3}$ See also, for example, Lemonnier I750: 5; Hanov I762: I3; Baumeister I747: I0; Meier I765: 20I-2; Erxleben I772: 2; Jacquier I785: I3. 
along with Leibniz's critiques. Together, these set the scene for the events of the I8th century.

In his Principles of Philosophy, Descartes set out to explain all natural phenomena by appeal to matter in motion. Descartes's "metaphysical physics" ${ }^{4}$ begins with his matter theory - an account of the nature of matter in terms of its essence, attributes and modes - and a definition of motion. ${ }^{5}$ All change comes about through collisions among the parts of matter, via the three laws of nature and the accompanying rules of collision. These rules of collision arise as a consequence of the nature of matter, and they are necessary for the explanation of all natural phenomena. As a result, the rules of collision lie at the intersection of metaphysics, matter theory, and physics. ${ }^{6}$

The foundational place of collisions in Descartes' project means that finding viable rules of collision becomes a foundational problem in natural philosophy. Reasons for dissatisfaction with Descartes's rules are not hard to find. On the one hand, it is not clear that the rules are consistent with his laws of nature, and even with one another. ${ }^{7}$ On the other, for those with any empiricist leanings, Descartes's claim that his rules hold for the tiniest parts of matter even if not for the motions of observable bodies (I99I, Part IV, paragraph 204), is not encouraging. In the mid I66os, the Royal Society of London conducted some experiments on collisions (Hall I966). Henry Oldenburg, ${ }^{8}$ then Secretary of the Royal Society, wrote to Huygens and Wren asking for their theories of motion and collision, and by December I668 the Royal Society had in hand information about rules of collision from Huygens, Wren and Wallis. ${ }^{9}$ In today's terminology, the rules of Huygens and Wren pertain to perfectly elastic collisions, while

${ }_{4}^{4}$ The term comes from Garber 1992.

${ }^{5}$ See Descartes I99I, Part II, especially $\$ 4$ and §25. For more on Descartes's matter theory, and the theory of matter in the I 7 th century more generally, see Jalobeanu and Anstey 20 II.

${ }^{6}$ There is a large and rich literature on science and philosophy in the I6oos that engages with many themes and issues from the broader historical context of the argument in this paper. We cannot revisit that here; our purpose in this section is to point narrowly to the I7th-century episodes that precipitate developments in the I70os, which are our main concern throughout the paper. The episodes we highlight here dovetail nicely with Alan Chalmers' studies of how matter theory and some parts of physics began to diverge, in the I7th century; cf. especially chapter 6-7 of Chalmers 2009.

${ }^{7}$ A thorough discussion of how Descartes' derived his rules, and whether they cohere with his laws, is the older Gabbey 1971; cf. Garber 1992 for additional explanation of Descartes' third law of nature.

${ }^{8}$ Oldenburg maintained a high profile and a prolific correspondence across the learned world, which he made available through the Philosophical Transactions of the Royal Society of London (Hall 2002).

${ }^{9}$ See Murray, Harper \& Wilson 201 I. 
those of Wallis pertain to perfectly inelastic collisions. Since these rules are familiar from collision problems in classical mechanics today, one might think that with the Huygens, Wren and Wallis rules of collision in place, the issue of collisions was resolved. Not so.

On December Ist, I668, Oldenburg wrote to Wallis asking a range of questions, including: ${ }^{\text {IO }}$

- Whether springiness is the only cause of rebounding

- Whether quiescent Matter has any resistance to motion

- Whether motion may pass out of one subject into another

- Whether no motion in the world perish, or new motion be generated

- Whether different motions, meeting, destroy one another

These questions concern the nature of matter, the properties of bodies, whether or not motion is conserved, and so forth. Notice that they do not pertain to whether or not the rules are correct; rather, they suggest that the rules by themselves are in some way incomplete or insufficient. Oldenburg put the point like this:

the Society in their present disquisitions have rather an Eye to the Physical causes of Motion, \& the Principles thereof, than the Mathematical Rules of it.

The issues at stake are put rather nicely by William Neile, in a letter to Oldenburg of I 8 December I668: ${ }^{\text {II }}$

I wish Dr. Wren would explain his principles a little more fully but he is against finding a reason for the experiments of motion (for ought I see) and says that the appearances carrie reason enough in themselves as being the law of nature. I think it is the Law of nature that they should appear but not without some causes....

I think a body cant be made hard without motion in its particles that is with out a spring and the more motion it has the more spring it has... I think all bodies are like fire only a masse of particles variously moving and sometimes resting...

\footnotetext{
${ }^{10} \mathrm{Cf}$. his letter in Oldenburg 1965-1986, 5: 220-222; for context and additional discussion, see Jalobeanu 20II.

${ }^{\text {II }}$ From Neile's letter to Henry Oldenbourg of I 8 December I668, in Oldenbourg 1965-86: 2634. For the historical envelope and philosophical analysis, see Jalobeanu 20II: I I 4-20. Neile was an exceptional young mathematician and fellow of the Royal Society who unfortunately died in his thirties.
} 
Neile is seeking an explanation for the rules of collision in terms of an underlying matter theory, just as we find in Descartes' theory. As noted above, Descartes's rules arise from the nature of matter, and from his metaphysical system more generally, including considerations of God's unchanging action in the world. Neile's point is this: the rules do not stand on their own; they must be integrated into a theory of matter. ${ }^{12}$

What this tells us is that, for some people at least, Descartes' Principles left two unresolved issues associated with collisions. First, the rules of impact required correction, and this was satisfactorily done (for a restricted set of cases ${ }^{13}$ ) by Huygens, Wren and Wallis. Second, the corrected rules needed to be appropriately connected to matter theory. This is the problem of collisions.

The problem persists through the remainder of the century. In I675, Malebranche published the first edition of his Search After Truth. In this text, he followed Descartes's model of associating rules of collision with a theory of matter. However, Malebranche diverged from Descartes: in his matter theory, he rejected Descartes' "force of rest" along with his claim that hard bodies rebound; for his rules of collision, he replaced Descartes' with those of Huygens, Wren and Wallis. Malebranche attempted to fit the two pieces together, but the upshot is not altogether satisfactory, and in I678 Leibniz published his Brief Demonstration of a Notable Error, which is best understood as a critique of Malebranche's theory of collisions. ${ }^{14}$ Leibniz argued that Malebranche's rules make use of the wrong conserved quantity, famously arguing for conservation of vis viva instead, ${ }^{15}$ and that they violate his supposed "law of continuity".

\footnotetext{
${ }^{12}$ We use the term "matter theory" for the philosophy of matter, including questions concerning the nature of matter, its qualities (essential and otherwise), and its behavior. Matter theory had a central place in early modern philosophy, as exemplified by Descartes's Principles of Philosophy (see above), as well as Hobbes' Leviathan, Boyle's Forms and Qualities, Spinoza's Ethics, Locke's Essay, Berkeley's Principles, Hume's Enquiry, and so forth (see Jalobeanu and Anstey, 20II: I; and also Gaukroger 2006, Chapter Io).

${ }^{13}$ The rules of Huygens, Wren and Wallis pertain to collisions that are perfectly elastic and inelastic, occurring between perfectly spherical bodies of uniform mass distribution (noting that these rules were formulated prior to Newton's development of his concept of mass), and for which the rotational motion of the bodies (as they roll towards one another) plays no role in the outcome of the collisions.

${ }^{14}$ For evidence Leibniz wrote Brevis demonstratio so as to object to Malebranche above all, see Robinet 2012.For analysis of the conceptual issues involved in their debate, cf. Brading and Stan, Philosophical Mechanics in the Age of Reason, ms.

${ }^{15}$ This is the origin of the so-called "vis viva controversy", for more on which see Hankins (1965), Laudan (1968), Iltis (1970), Papineau (1977), Terrall (2004), Smith (2006), Reichenberger (20I2), and references therein.
} 
Malebranche's main concerns lay far from collision theory; yet, in following Descartes, he placed collisions at the basis of his natural philosophy, and so deal with the problem he must. Perhaps reluctantly, he tweaked his rules for hard body collision, but Leibniz was not satisfied, issuing more critiques (I692, I693, I698) and engaging in disputes with followers of Malebranche, until in I700 Malebranche offered a fully revised theory of collisions in the fifth edition of the Search After Truth. ${ }^{16}$ And with this, neatly for our story, we arrive at the opening of a new century.

\section{What's the problem?}

A review of early i8th century natural philosophy sheds further light on the problem of collisions, and reveals it to have been of widespread concern, as we shall now see.

Malebranche's (1700) mature theory of collisions proceeds as follows. It begins from the nature of matter as in itself soft, and from there constructs three kinds of bodies: soft, hard, and elastic. Soft bodies are regions of soft matter, relatively at rest with respect to one another. Hard bodies are also such regions, differing from soft bodies in that they are compressed by the surrounding subtle matter. Subtle matter is simply soft matter, moving at high speeds relative to the quiescent region of soft matter that it compresses into a hard body. Elastic bodies too arise from soft matter, but in their case they contain pores, through which the subtle matter passes. These three kinds of body are distinguished from one another in collisions by their shape behavior: on impact, soft bodies undergo irreversible deformation, whereas hard bodies undergo no deformation at all. Elastic bodies undergo reversible deformation. What is to be explained, given these resources, is the kinematic behavior of these bodies in collision: elastic bodies rebound, whereas hard and soft bodies do not. Malebranche seeks to explain this, and thereby explain the rules of collision, by describing the process of collision in terms of his theory of matter. For example, in the case of elastic bodies, subtle matter is squeezed out of the pores of these bodies during the initial phase of the impact (so the body deforms and compresses), and rushes back in during the second stage (the body recovers its initial shape and rebounds).

\footnotetext{
${ }^{16}$ See Brading and Stan, Philosophical Mechanics in the Age of Reason, ms., chapter 2, for the details of this story.
} 
What we see here is Malebranche striving to provide an account of the collision process that integrates the rules of collision into his matter theory. The intermediate step is his account of bodies. His theory of matter provides the resources for the construction of bodies: their nature and their properties. The rules of collision say how the motions of bodies are changed by mutual impact. An adequate theory of matter will provide bodies whose nature and properties are sufficient to explain the behaviors described by the rules of collision. In this way, the problem of collisions became a test of matter theory: any satisfactory matter theory had to be capable of yielding an account of bodies adequate for the explanation of collisions. As for Descartes, metaphysics, matter theory and physics are inextricably entwined.

The integration of the rules of collision into a theory of matter is what any viable solution to the problem of collisions was expected to achieve. Despite his best efforts, Malebranche's account was not accepted as a success. The problem remained unsolved, and was taken up by his followers and critics alike. ${ }^{17}$

It was not just the "Cartesians," such as Malebranche, who pursued this problem. We see self-proclaimed "Newtonians," such as John Keill (I700) along with 's Gravesande (I720), Musschenbroek (I744), Pemberton (I728), MacLaurin (I728) and so forth, undertake the same task, albeit with modifications reflecting the differing epistemologies and methodologies. Keill, for example, divides bodies into three kinds (hard, soft and elastic) according to their material properties, and then seeks to combine this taxonomy with two sets of rules of collision (one for rebound and one without) via a causal explanation of how the material properties yield the collision outcomes for each kind. However, the relation between his three-way taxonomy and his quantitative dynamical rules remains stipulative: Keill says that the former grounds the latter, but he is unable to derive the one from the other. ${ }^{18}$

The same foundational concern - to integrate collision rules with a sound philosophy of body - animated the Germans. We have already seen that Leibniz took the problem of collisions very seriously, challenging Malebranche's account, and a discussion of collisions is one strand running through The Leibniz-Clarke Correspondence of I715-I6. As early as I669 Leibniz had expressed dissatisfaction that the Wallis-Huygens-Wren rules were left unexplained. "For [Leibniz] seems to think that neither you nor Mr. Wren have assigned the causes

${ }^{17}$ See Brading and Stan Philosophical Mechanics in the Age of Reason ms. for more details.

${ }^{18}$ Again, see Brading and Stan Philosophical Mechanics in the Age of Reason ms. for details. 
of these Phenomena that you examined in establishing your rules," Oldenbourg told Huygens. ${ }^{19}$ Much of his later work in natural philosophy famously amounted to finding a doctrine of matter adequate for grounding the rules. He thought he found it in a conception of body qua essentially endowed with force-in particular, derivative forces, which "suffer modifications" in impact. The rules of collision spell out precisely that modification, under the general principle that overall force is conserved (in the system of interaction).

Leibniz's disciples continued this agenda. Jakob Hermann sought to connect the collision rules with two kinds of force (responsible for elastic and inelastic impact, respectively). Then Christian Wolff expanded the perspective, by integrating impact rules not just with matter theory, but with an ontology of body more generally. ${ }^{20}$ Just like Descartes, he kept collision at the heart of his natural philosophy: "no change can occur in bodies except by means of collision" (Wolff I73I: 244). And, he emphasized that ultimately metaphysical principles are needed to ground the rules: "Implicit in the rules of motion are certain general principles, from which these rules can be derived. ... It is the business of Metaphysics to demonstrate those principles" (I73I: 228). In sheer volume and detail, his account exceeded all other similar attempts in the early Enlightenment. ${ }^{21}$

In sum, the Leibnizians likewise took up the post-Cartesian challenge. In every case, the goal was the same: to provide a causal-explanatory account of the collision process that integrates the rules of collision into a theory of matter. As of the early century, no proposal had met with general acceptance.

As this brief overview indicates, the topic of collisions received widespread attention in the early I700s. This is not surprising since, from Descartes onwards, collisions lay at the foundation of natural philosophy. This was true even for those Newtonians who, after Newton's Principia, embraced action-at-a-distance in their treatments of gravitation, for they too retained collisions among

\footnotetext{
${ }^{19}$ Oldenburg to Chr. Huygens, 7 April I67I, in Huygens (I897: 56).

${ }^{20}$ Hermann's collision theory is in chapter VI of his Phoronomia (I7I6: IIO-24). Christian Wolff took up the project in the I720s, and completed it with an extensive account of collision, both elastic and inelastic, derived from his philosophical physics, in Cosmologia generalis (I73I: §§ 363-502).

${ }^{21}$ Later in the century, the young Kant would take up this foundational agenda, outlining his collision theory in a I $75^{8}$ paper, "New Doctrine of Motion and Rest" (Kant I9I2). He designed a theory of matter (or "physical monadology", based on a species of mass points) and a causal dynamics of impact, from which he derived rules of inelastic collision. Like those before him, he regarded the rules as insufficient on their own, because they describe "only the outer phenomenon of what occurred immediately between [the colliding bodies]; and it is the latter that one needs to know," he asserted. For analysis, see Stan 2009.
} 
bodies as one means of causal interaction. In short, everyone needed a theory of collisions. Moreover, there were widespread commonalities in the criteria for success. With all of this interest and effort, a solution might reasonably have been expected. Why, then, did the problem become acute?

\section{The problem becomes acute: three reasons}

Against this backdrop, we suggest three reasons why the problem of collisions became acute by the mid I8th century: intelligibility, intractability, and scope. To preview: (I) the very intelligibility of contact action was seriously challenged; (2) attempts to solve the problem of collisions, success at which might be expected to address the issue of intelligibility, proved unsuccessful; and (3) the treatment of collisions was not an issue local to physics but had ramifications across philosophy quite generally.

Let's begin with the first reason. Disputes over the intelligibility of actionat-a distance placed action-through-collisions in the spotlight. The LeibnizClarke Correspondence (Alexander 1956) opens with questions of God's presence and action in the world, and quickly turns to the issue of how one body acts on another, both in collisions and also, more famously, in accordance with Newton's theory of gravitation. Leibniz wrote:

But then what does he mean, when he will have the sun to attract the globe of the earth through an empty space? Is it God himself that performs it? But this would be a miracle, if ever there was any....

... That means of communication (says he) is invisible, intangible, not mechanical. He might as well have added, inexplicable, unintelligible, precarious, groundless, and unexampled.

... If the means, which causes an attraction properly so called, be constant, and at the same time inexplicable by the powers of creatures, and yet be true; it must be a perpetual miracle: and if it is not miraculous, it is false. 'Tis a chimerical thing, a scholastic occult quality. (Alexander I956: 94)

In contrast with gravitation, Leibniz held contact action to be intelligible. Yet debates continued over how to theorize contact action, with the controversy over vis viva being the most famous strand of these debates. In the midst of all this, the onus falls on those wielding the weapon of intelligibility to show that collisions satisfy their criterion. 
What would this involve? The parallel with Newton's theory of gravitation is instructive. Newton provided a mathematical rule for the behavior of bodies acting on one another via gravitation. The rules of collision can be thought of as analogous. Leibniz demanded that the rule for gravitation be rendered intelligible in terms of an underlying theory of matter, one which showed how it is that one body acts on another such that the upshot is motion in accordance with the law of gravitation. The analogous demand is to provide an account of the collision process, in terms of an underlying theory of matter, that renders intelligible how it is that one body acts on another such that the upshot is motions in accordance with the rules of collision. As we have seen, there was no generally accepted solution to this problem.

The high profile disputes over the intelligibility of Newtonian gravitation raised the visibility of the problem of collisions. As we will see in more detail below, Maupertuis in 1732 argued that, qua form of action between bodies, contact action via a motive, or "impulsive," force is no more intelligible than is Newtonian action-at-a-distance. Contact action seems intelligible only because it is familiarly common: we have often seen collisions among bodies, and so we are accustomed to it. This increased visibility contributed to the pressure on finding a solution.

Had a solution been forthcoming, the intelligibility issue might have been resolved as part of that solution. However, the second reason why the problem of collisions became acute is decades of failure in attempting to solve it. Admission of failure was given institutional expression in France. In the I720s-forty years after the Royal Society of London discussions of collisions-the Paris Academy of Sciences offered two prize competitions on the topic. The first, in I724, posed this question: "Which are the laws whereby a perfectly hard body in motion will move another body of the same nature through collision, be it in a vacuum or in a plenum?" The entries make clear that merely offering Wallis's rules would be insufficient as an answer: a causal explanation of hard body collisions was expected and required. Far from resolving the issue, the competition made the difficulties even more visible. Moreover, because Johann (I) Bernoulli sought to provide an account in terms of elastic bodies, the competition on hard body collisions highlighted the difficulties with elastic body collisions too. In I726, the competition was on "the laws of impact between bodies with recoil, perfect or imperfect, deduced from a probable explanation of the physical cause of recoil" (emphasis added). As this statement of the topic makes clear, the Academy sought an explanation of the rules of elastic collision in terms of underlying physical causes. Entries included attempts at such an account using 
subtle matter. Indeed, the winning paper explained elastic compression, shape restoration, and rebound based on microscopic vortices of subtle matter, the approach that Malebranche had pioneered in I700. And like Malebranche's own theory, it failed to convince. We are now 80 years from Descartes's Principles of Philosophy, and there is still no satisfactory account of collisions. ${ }^{22}$

In our opinion, the high-profile dispute over the intelligibility of Newtonian gravitation along with the persistent failure to solve the problem of collisions worked together to make the problem acute. With this in mind, we can see Maupertuis in 1732 challenging his fellow French philosophers head-on when he writes that the means by which bodies act on one another through the "impulsive force" of collision is no more intelligible than the attractive force of gravitation:

The common People are not at all surprized when they see a Body in motion communicate its Motion to others, for being used to this Sight they see nothing wonderful in it: but Philosophers who are resolute enough to decide a priori concerning what Properties are to be admitted in Bodies, and what excluded; such Philosophers I say cannot conceive the impulsive Force more conceivable than the attractive. What is this impulsive Force? How does it reside in Bodies? Who could have imagined it to have been resident therein, before he had seen the shock or congress [i.e. the collision] of Bodies? (Maupertuis I734: I4)

There are several targets in Maupertuis' text, but for our purposes the important point is that he is seeking to put attraction and contact action on an equal epistemic footing, and he is doing so by pointing out the inadequacy of the existing causal-explanatory accounts of collisions. ${ }^{23}$

If you have ever wondered why, in his discussion of causation, Hume seems obsessed by the example of billiard balls, you now have your answer. Hume was writing his Treatise in France in the I730s, when the problem of knowing the causes of how one body acts on another during collisions was a high profile, much-discussed, unsolved problem at the foundations of physics. Hume's fellow Edinburgh Scot from a generation before, John Keill, had argued that constant conjunction is evidence of cause (Keill I720: 90). He did so to argue from

\footnotetext{
${ }^{22}$ For discussion of the 1724 competition and ensuing developments, see also Scott 1970, chs. 2 and 3. Scott's focus is on hard-body collisions, and he frames the debates in terms of atomism versus conserved quantity approaches to collisions. To our knowledge, this is the only other text to place collisions center stage.

${ }^{23}$ The broader challenge is to the criteria for any such account, and this theme is taken up by his friend Euler, as we will see below.
} 
accepted cases of our knowledge of causation (such as collisions) to claims about causal knowledge of gravitational attraction. With the difficulties in providing an account of the causal process of collision becoming ever more evident, Hume turned that argument on its head.

The same skeptical refrain - that impulsive action is unintelligible-comes from d'Alembert too, amplified for maximum resonance in the Encyclopedie:

we do not know, and likely will never know, by what power this change (of motion in impact) is effected, and why a body that collides with another does not just come to rest after impact-without communicating some of its motion to the impacted body. (d'Alembert I778: 932)

Thus by the I750s, the old wisdom that collision is eminently intelligible had gone bankrupt.

The above two reasons are together sufficient for the problem to have been acute at the time. There is one more that shows the depth and gravity of what was at stake. It lurks in the background, rarely addressed explicitly, but a little reflection brings it readily to light. The problem of collisions, we claim, was a problem not just for physics (that is, for natural philosophy) but for philosophy much more generally. To see this, one need only note that among the bodies in the world are human bodies. To have an account of human bodily action, one must first have an account of bodily action generally. After all, if I am to use my hand to help you up from your chair, my body must act on yours; to turn on the light, I must move the switch. ${ }^{24}$ Any area of philosophy that presupposes human bodily action therefore depends on an account of bodily action, and so finds itself entangled with the problem of collisions. Descartes's philosophy is a case in point. For Descartes, the embodied human being acts on other bodies in accordance with the laws of nature and the rules of collision, and one suggestion for how this might be so is this: while the laws and rules determine much about the outcome of collisions, they do not determine the direction of motion in many cases, and it is here that the human soul may intervene, selecting the $d i-$ rection of motion, though having no bearing on the quantity of motion. ${ }^{25}$ Come

\footnotetext{
${ }^{24}$ We do not here distinguish intentional bodily actions from bodily actions generally, for the former are a subset of the latter.

${ }^{25}$ It is controversial whether this view can be attributed to Descartes himself. See Schmaltz 2008, §4.3.3, and also Pitts, "The Mind-Body Problem and Conservation Laws: The Growth of Physical Understanding?" ms., and references therein.
} 
the I730s, Du Châtelet worried about Leibniz's principle of conservation of living force and its implications for free human action. In her account of free will, two elements are required: a will governed by reason and the physical power to act: an account of how it is that one body can act on another is a prerequisite for an account of human action.

This makes the problem of bodily action relevant not just for natural philosophy but for moral and political philosophy too. In the early decades of the I8th century, these disparate areas of philosophy shared a common conception of body, and this conception of body thereby played a unifying role. Physics was that branch of philosophy expected to provide all of philosophy with an account of body in general, including its nature, powers, properties, causes, effects, origins, attributes, modes, and so forth. This upshot is worth pausing over. Body-body action is not "merely" a foundational problem for I 8th century natural philosophy, it is a problem with much wider ramifications and implications.

Taken together, these three reasons - concerning intelligibility, intractability and scope-enable us to see why such an apparently humdrum problem within the foundations of physics came to be painfully acute by the I730s and $40 .^{26}$

\section{Du Châtelet responds}

From her letters, and from the topics discussed in her 1740 Institutions de Physique (Foundations of Physics), it is clear that Du Châtelet sought an account of bodies and bodily action adequate for the purposes both of physics (or natural philosophy) and of philosophy more generally. Within this context, we can read her as responding to Maupertuis' challenge to render bodily action intelligible, and her adoption of the Principle of Sufficient Reason (PSR) as her criterion of intelligibility. She deploys PSR in her examination of gravitation, thereby ruling out attraction. She also uses PSR in developing her account of bodies and their forces, which she depends on in discussing contact action. Her account of collisions is the most developed attempt of the period to provide a causal explanation of the process by which one body acts on another during the collision process, in terms of a theory of matter, and such that the rules of collision are

\footnotetext{
${ }^{26}$ As we noted above, the issues had long-since been raised in the $\mathrm{I} 7$ th century, but it is the changing context in the I8th century, outlined in this section, that raises the visibility and salience of the problem.
} 
integrated into that theory of matter. This makes its successes-and failuresof particular interest.

According to Du Châtelet, bodies arise from simple substances. These simples are not themselves extended, but have primitive active and passive force. Multiplicities of these simples give rise to bodies as we experience them. Such bodies have three essential properties: extension (shape and size); derivative passive force (by which they resist changes in motion); and derivative active force (which is the principle of change in bodies and the means by which they act on other bodies). This active force in turn manifests itself as either dead force (when a body's motion is impeded by another body) or living force ("vis viva") when a body is in motion.

Du Châtelet offers a qualitative account of the collision process, which proceeds roughly as follows. Each body has a quantity of active force. When bodies press upon one another during a collision, active force manifests itself as dead force. Once the active force of one body is used up, it can no longer act on the other body but merely resist (through its passive force), and the remaining active force of the other body now manifests itself as living force; the two bodies begin to move. This qualitative process is then connected up to quantitative results (including those associated with the rules of collision) by associating the Leibnizian conceptions of force described above with her revised versions of Newton's three laws of motion. This is the most promising attempt at an integrated, causal-explanatory account of collisions from the first half of the $\mathrm{I} 8^{\text {th }}$ century, yet it is riddled with problems. It is not clear that the qualitative account is conceptually coherent, and it is not clear that one can arrive at a quantitative account by connecting the Leibnizian notions of force with Newton's three laws of motion, even in the revised form that Du Châtelet offers them, in a coherent way. Moreover, even if these hurdles are overcome, it is very difficult to see how to make the account consistent with actual experimental results whilst retaining its explanatory power. ${ }^{27}$ We will not dwell on the details here. Our point is simply to note that the best account available at the time faced considerable difficulties. With this situation in mind, we can turn our attention to an alternative path ahead.

\section{Philosophical Mechanics}

${ }^{27}$ For more details, see Du Châtelet, relevant chapters, and Brading (20I9) chapter 4. 
Our discussion so far has focused on physics, as it was understood at the time: the study of bodies, including their nature, properties, powers, causes and effects. As we have noted, it was the job of physics to provide a general account of bodies, suitable for philosophy in general. Moreover, physics provided the bodies that served as the subject-matter of mechanics, in a sense that will become clear in what follows. At the time, physics was distinct from mechanics. This can seem puzzling to those of us who use the labels "classical physics" and "classical mechanics" interchangeably, even when thinking of developments in the I8th century due to such figures as Euler, d'Alembert, and Lagrange. Nevertheless, if we are following the story forwards in time, rather than looking backwards through our present-day spectacles, distinguish them we must.

"Physics" was a term often used interchangeably with "natural philosophy" at the time. We have seen Musschenbroek's description of the goals and subject-matter of physics, and this was then a widely shared conception of physics or natural philosophy. The term "mechanics", on the other hand, had a multitude of uses, from the science of machines to the various strands of "mechanical philosophy", but here we use it with one particular connotation, in use at the time and broadly familiar from present-day usage. Specifically, we are interested in rational mechanics, the problems and methods of which (no matter the various labels at the time) fell within the domain of mathematics. Under the label of "rational mechanics" we include traditional problems in statics (such as the mathematical treatment of the lever), as well as the study and development of new problems involving motion (such as the pendulum, brachistochrone and bead-on-a-wire), using geometry and, increasingly, methods that incorporated the new mathematics of Leibniz and of Newton. While some people at the time, including some of the most influential figures of the period, were both philosophers and mathematicians, the two disciplines were distinct. They had distinct methods, distinct goals, and distinct domains of authority. Our use of the term "rational mechanics" is one that came to dominate by the end of the I8th century, and it can be found explicitly one hundred years earlier in the Preface to Newton's Principia. ${ }^{28}$

\footnotetext{
${ }^{28}$ The first two books of Newton's Principia consider motions and forces considered mathematically, and in the third book-where we consider the motions of the bodies in our planetary system - we proceed to physics. In "coming down" from rational mechanics to physics (Newton, I999, p. 588), we first determine which forces are actual (i.e. which of the force laws explored by rational mechanics pertains in the behaviors of actual bodies), and then we seek the causes of these forces. For discussion of the role of mechanics in Newton's Principia see Domski (2003) and Gabbey (1992).
} 
For Newton, rational mechanics and physics are both parts of natural philosophy, but this choice of labels is confusing because the terms "physics" and "natural philosophy" were so often used interchangeably. To avoid this confusion, we adopt the term "philosophical mechanics" to cover those projects, such as Newton's Principia, which sought to combine rational mechanics with physics. ${ }^{29}$ The term captures the attempted unification and integration of results in rational mechanics, such as the rules of collision, with the goals and resources of physics (or natural philosophy), which at that time sought a matter theoretic causal understanding of the nature, properties, and behaviors of bodies.

Physics and mechanics worked with a common subject-matter: bodies. However, it was physics that was authoritative as to the nature and properties of bodies, and so it was the philosopher who provided the account of bodies that were the subject-matter of mechanics. The mathematician, working in rational mechanics, abstracted from the properties of bodies treated by the philosopher to consider only those relevant to the mathematical treatment of the motions of bodies. This allowed mechanics to simply presuppose the existence of the bodies that are its subject-matter, and from there develop largely independently of physics (as, for example, in the work of Galileo). In philosophical mechanics, the attempted integration of physics and mechanics begins from this presumption of a shared subject-matter: the bodies that are the subject-matter of physics are also those studied in rational mechanics.

Descartes's Principles of Philosophy, Part II, in which he attempts to combine quantitative rules of collision with his theory of matter, is an example of philosophical mechanics. The treatments of collisions we have mentioned so far, from Malebranche to Du Châtelet, are also examples of philosophical mechanics. These approaches all have three things in common. First, they begin with the physics, and seek to recover, or otherwise arrive at, the mechanics from there: they are physics-led approaches to philosophical mechanics. Second, given the conception of physics at the time, it is from the theory of matter that such a physics takes its resources in constructing bodies. Finally, as we have seen, when it came to the problem of collisions, none succeeded..$^{3}$

\footnotetext{
${ }^{29}$ The term was first used (to our knowledge) in a French text on mechanics by Gaspard Prony (1799). In our book, Philosophical Mechanics in the Age of Reason, we adopt it for our own purposes.

${ }^{30}$ Our point here dovetails with the general lessons that Mark Wilson has drawn about the elusive ways in which rational-mechanical formalism and various pictures of matter become entangled in "classical mechanics". Our paper reinforces his lesson from a historical vantage point. Cf. his discussion of "Newtonian" accounts of collision, in Wilson (forthcoming). Some of the papers in his 2018 enlarge the perspective beyond impact mechanics.
} 
With the framework of philosophical mechanics in mind, an alternative presents itself: we might begin instead from rational mechanics, and hope for success by this route. One person who proceeded in this way was Leonard Euler.

\section{Euler's collision theory}

In I736, Euler published his Mechanica in which he outlines a project of treating the motions of bodies, beginning with the motion of point particles and moving from there step-by-step through the treatment of extended bodies (both rigid and flexible) moving under constraints, to the treatment of collisions.

That was his plan. In practice, however, the two published volumes of $M e-$ chanica concern solely the motion of point particles, and neither contains a treatment of collisions. This tells us something important: collisions are not foundational for Euler's mechanics; their treatment is a complex problem to be arrived at through first solving simpler cases (the motions of point particles, free motions of extended bodies, constrained motions of extended bodies, etc.), and the rules of collision are to be recovered within this wider system of mechanics.

Euler developed his theory of collisions in a series of papers in the 1740 s and 50s. In his Mechanica, he had attributed a set of properties to bodies, as necessary for the solution of problems in mechanics: extension, inertia, and impenetrability. In his collision papers, his starting point is this set of properties. First, he argues from bodies as extended, inertial and impenetrable to a general condition on the rules of collision. As a rational mechanics, these results are limited, for they take as primitive properties of extended bodies (rigidity, elasticity, and so forth) that Euler had yet to treat systematically in his mechanics. His goal was not primarily mechanics, but the integration of physics and mechanics: a philosophical mechanics. Euler's next step is to argue that impenetrability is the origin of the force that causes the change in a state of a body in collision. Moreover, Euler argued, having identified this cause we have met the demands of physics. In short, we begin from mechanics, which gives us the properties of bodies in general, and from there develop both the rules of collision and a physics of collisions. This is Euler's solution to the problem of collisions.

The details of this proposal are not important for our present purposes. ${ }^{3 \mathrm{I}}$ What matters for our story is Euler's understanding of the goals of physics, and

\footnotetext{
${ }^{3 \mathrm{I}}$ See Brading and Stan, Philosophical Mechanics, chapter 5, for the details.
} 
of the relationship of physics to rational mechanics. In an unpublished manuscript from the I750s, Natural Philosophy, Euler is explicit in his conception of natural philosophy. He writes: "Natural philosophy is a science that aims to explain the causes of changes that occur in bodies" (I862: 57; our translation). That natural philosophy has bodies as its subject-matter, and that it is concerned with causes, aligns with the conception of physics (or natural philosophy) offered by Musschenbroek. However, the emphasis on changes is a significant difference. Euler writes:

Whoever can point to the reason why a change has occurred, has found its cause, and thus fulfils the ultimate aim of Natural Philosophy...

This ultimate aim is focused only on changes... (Euler I862: 57; our translation)

The upshot of this is that the aim of natural philosophy is to determine all and only those properties of bodies relevant to the changes that bodies undergo, and to give the causes of those changes. Since only extension, inertia, and impenetrability are relevant for deriving the rules of collision, and since impenetrability can be shown to be the cause of the changes bodies undergo as a result of collision, Euler's account is sufficient to fulfil the aims of physics. Or so he claims.

Euler's justification for appealing to extension, inertia, and impenetrability in his account of bodily collision is rational mechanics: it is through the mathematical treatment of the motions of bodies that we discover the most general properties of bodies. Rather than physics providing rational mechanics with a general conception of bodies and their properties, for Euler it is the other way around: rational mechanics acts as a constraint on matter theory. ${ }^{32}$ In other words, it is the "mathematicians", working in rational mechanics, who claim authority over the most general properties of bodies. That task had, until this time, lain in the domain of the philosophers, as the task of physics.

In his paper on space and time (1750), Euler states his position unequivocally. The principles of mechanics are so firmly established that their truth is not to be doubted. Moreover, these principles depend upon the nature of bodies, and so any philosophical claims about the nature of bodies must be consistent

${ }^{32}$ Euler's position is in fact more complicated, since he also endorsed an a priori method for arriving at the general properties of bodies. More work is needed on Euler's epistemology and his theory of matter. 
with the requirements arising from mechanics. Indeed, the principles of mechanics can serve as a guide to metaphysical reasoning. In Euler's taxonomy, physics can still treat specific kinds of bodies, but rational mechanics-in treating the motions of bodies in general-has priority and authority over the general properties of bodies. What we see happening here is best described as a territory grab, with far-reaching consequences. Instead of taking its subjectmatter from physics, mechanics now supplies its own subject-matter: body in general. More than that, mechanics supplies the general conception of body for the rest of natural philosophy, and indeed for philosophy more widely. ${ }^{33}$

And this is where we see physics begin to slip out of the philosophers' nest. For, insofar as physics is the science of bodies in general, including their natures, properties, causes and effects, it is no longer the philosophers but now the mathematicians who have authority over these issues. It is the mechanics of the mathematicians, rather than the matter theory of the philosophers, from which we are to determine the properties of bodies in general. Left to the philosophers is "special physics", the treatment of specific kinds of bodies (though not for long, as the I9th century would show), and "metaphysics", which studies that which is "common to all created beings" (assuming there is such a category beyond general body itself). The "mathematicians," the practitioners of rational mechanics, expand their territory to include all legitimate questions pertaining to "body in general," and thus steal physics (or at least "general physics") away from philosophy.

We can sum up as follows. Recall our definition of philosophical mechanics as providing a treatment of the behavior of bodies that unifies the goals of physics (through a causal account of the behavior of bodies in terms of their nature, properties, and so forth) with those of rational mechanics (providing a quantitative treatment of those behaviors, and in particular their motions). In his theory of collisions, Euler sought to provide a unified, causal-explanatory account of the collision process: he sought a philosophical mechanics of collisions. Importantly for our story, his philosophical mechanics begins from mechanics.

\footnotetext{
${ }^{33}$ In the space and time paper (I750), Euler states that his confidence in mechanics arises from strong quantitative empirical success: "the marvelous accord of all the conclusions that one obtains through calculation, with all the motions of bodies on earth both solid and fluid and even with the motion of celestial bodies, shall be sufficient to put their truth beyond doubt." However, with the exception of celestial mechanics, rational mechanics in the I8th century developed with surprisingly little connection to quantitative empirical results, and the epistemic status of its principles is more complex than Euler's position here implies.
} 
More importantly still, Euler's ambitions for mechanics reach far beyond collisions. It is not simply for the purposes of collisions that rational mechanics has priority: it is for the concept of body quite generally.

In the context of I 8 th century philosophy, this is a bold ambition: we seek a single concept of body that will serve not just for "general physics" and mechanics, but also for "special physics", and importantly also for the human body, accounts of embodied human action, and so forth. This concept of body should thereby provide a unifying, common subject-matter across philosophy. Could Euler's rational mechanics supply a general concept of body adequate for the needs of philosophy?

The answer is no. Not just Euler, but I8th century mathematicians as a whole, did not have a completed rational mechanics of extended bodies: arriving at such a thing was a work-in-progress. ${ }^{34}$ Indeed, collisions pose such a very difficult and complex problem that even incorporating the rules of collision into a systematic rational mechanics had yet to be achieved. We saw above that collisions are not a foundational problem for rational mechanics, and that Euler's treatment of collisions presupposes rigid bodies subject to highly idealized conditions: arriving at these rigid bodies along with a more generalized treatment of collisions, from within a general theory of rational mechanics, is a formidably complicated task whose solution existed only as a promissory note.

Where does this leave us? The natural philosophers' physics-first approach to philosophical mechanics had failed to provide a satisfactory theory of collisions. The mathematicians' mechanics-first approach, championed by Euler, stole authority over the general properties of bodies ("general physics") from natural philosophy and placed it in the domain of mechanics. But, as of the late I8th century, mechanics had failed to deliver a general account of body adequate for the needs of philosophers. So what?

\section{So what for philosophy? So what for physics?}

Where did this leave philosophy? Looking back, it seems to us that there are four responses available to philosophers of the late $\mathrm{I} 8$ th century. The first is for philosophers to shut up shop, go home, and wait for the new "science of bodies in general" to be completed, whenever that might be, before continuing. This

\footnotetext{
${ }^{34}$ For an overview of the efforts to build a broad-scope rational mechanics in the Enlightenment, see Caparrini \& Fraser 2013.
} 
is hardly practical. The second is to proceed with caution, paying careful attention to the developments in the science. This is something Kant tried to do. Unfortunately for him, mechanics moved on ahead of him (Stan 2015), but the general approach is one found among some philosophers of physics today. The third is to proceed in bolder fashion, making claims as to the autonomy of one's philosophical project from the details of the whatever the "science of bodies in general" turns out to be. Philosophers nowadays are known to make such remarks as "Whatever physics turns out to say about the fundamental ontology of the world, dot dot dot", and then make their claims, thus presuming both autonomy from the details and consistency with those details (not always successfully). And finally, philosophers might say, "so much the worse for physics in struggling to give an account of its own subject-matter", and proceed to develop independent accounts of the subject-matter of different areas of philosophy, from the "specific physics" of special kinds of bodies, such as chemical bodies, and living bodies, to the human bodies of moral and political philosophy, and so forth, thereby fragmenting our concept of body. We can recognize this approach in philosophy today, too.

What about physics? Whereas at the beginning of the I8th century, matter theory provided the resources from which the subject-matter of physics was constructed—bodies-by the late I8th century those resources were to come from mechanics. Insofar as mechanics is able to supply these resources (and the presumption of Euler's project is that it could), then the ontology of the new physics is autonomous from philosophy. Moreover, when it comes to epistemology, mathematicians sought warrant and justification for the results of mechanics in the mathematical methods and the quantitative empirical successes of mechanics itself. In this way, physics flew the philosophers' nest, achieving (or at least aspiring to) an autonomy in both its ontology and its epistemology. Evaluating the extent of the success is a project for philosophers of physics today.

We have over-simplified the story, of course. On the one hand, attempts to integrate mechanics and matter theory recur throughout the nineteenth century and beyond. On the other hand, a great many other factors were at work. But we stand by our central claim: the failure of philosophers to solve the problem of collisions, as they understood it, played a pivotal role in driving physics and philosophy apart.

At the outset we asked: What happened? - And, what philosophical lessons should we take away? If we look at the I 8 th century, and the rise of mechanics, our view is that terrestrial mechanics has been underappreciated as a source of 
philosophical difficulties, in comparison to celestial mechanics. It is true that the I8th century saw extraordinary successes in celestial mechanics, and that this gave great prestige to the "mathematicians" and the practitioners of rational mechanics, at the expense of the "philosophers." However, throughout all of this the subject-matter of philosophy and celestial mechanics might have remained one and the same, with physics (understood as a part of philosophy) providing the account of the bodies that are the subject-matter of celestial mechanics. In that case, while the physics of the philosophers and that of the mathematicians might have drifted apart due to social and political factors, philosophically they would have remained unified by a shared subject-matter.

The case of terrestrial mechanics is different. Here, we find philosophical reasons for the split. Faced with the long term and persistent failure of philosophers to solve the problem of collisions, Euler re-conceptualized the aims of physics, and turned to rational mechanics for the resources necessary to pursue physics. This reconceptualization was successful for the purposes of mechanics and general physics, but unsuccessful more generally, for it failed to provide a general concept of body suitable for the purposes of philosophy. As a result, the subject-matter of philosophy was severed from that of the newly conceptualized physics. It is this ontological dis-unification, we claim, that sits at the heart of the split between physics and philosophy. To go back to where we began: it was the problem of collisions that led to physics flying the philosophers' nest.

\section{Acknowledgements}

We are grateful to participants at The Society for the Metaphysics of Science 2019 conference and the Princeton-Bucharest Virtual Seminar in Early Modern Philosophy 2020, the members of the Duke Philosophy Department, and to an anonymous reviewer for their comments.

\section{References}

Alexander, H. G. ed. 1956. The Leibniz-Clarke Correspondence: Together with Extracts from Newton's Principia and Opticks. Manchester: Manchester University Press.

Baumeister, Fr. I747. Elementa philosophiae recentioris. Leipzig.

Brading, K. 2019. Émilie Du Châtelet and the Foundations of Physical Science. Routledge. 
Caparrini, S. and Fraser, C. 2013. Mechanics in the Eighteenth Century. The Oxford Handbook of the History of Physics, ed. J.Z. Buchwald and R. Fox, 358-405. Oxford University Press.

Chalmers, A. 2009. The Scientist's Atom and the Philosopher's Stone. Springer.

D’Alembert, J. I778. Attraction. Encyclopédie, ou dictionnaire raisonné, eds. J. D’Alembert \& D. Diderot, vol. 3, 917-35. Lausanne and Bern: Sociétés Typographiques.

Descartes, R. I99I. Principles of Philosophy, trans. V. R. Miller and R. P. Miller. Dordrecht: Kluwer.

Domski, M. 2003. The Constructible and the Intelligible in Newton's Philosophy of Geometry. Philosophy of Science 70: II I 4-I I24.

Du Châtelet, E. I742. Institutions physiques. Amsterdam.

Ducheyne, S. 2015. Petrus van Musschenbroek and Newton's 'vera stabilisique Philosophandi methodus'. Ber. Wissenschaftgesch. 38: 279-304.

Erxleben, J.P. I772. Anfangsgründe der Naturlehre. Göttingen.

Euler, L. I750. Reflections sur l'espace et le tems [I748]. Memoires de l'academie des sciences de Berlin 4: 324-333.

Euler, L. I862. Anleitung zur Naturlehre. [E842]. Opera Postuma, ed. P.H. Fuss, vol. 2, 449-56o. Saint Petersburg.

Gabbey, A. I97I. Force and inertia in seventeenth-century dynamics. Studies in History and Philosophy of Science 2: I-7I.

Gabbey, A. 1992. Newton's ‘Mathematical Principles of Natural Philosophy': A Treatise on Mechanics? The Investigation of Difficult Things. Essays on Newton and the History of the Exact Sciences in Honour of D. T. Whiteside, eds. P. Harman \& A. Shapiro, 305-22. Cambridge University Press.

Garber, D. 1992. Descartes' Metaphysical Physics. University of Chicago Press.

Gaukroger, 2006. The Emergence of a Scientific Culture: Science and the Shaping of Modernity, I2IO-I685. Oxford University Press.

Hall, A.R. I966. Mechanics and the Royal Society, I668-70. The British journal for the history of science 3: 26-38.

Hall, M. B. 2002. Henry Oldenburg: Shaping the Royal Society. Oxford University Press.

Hankins, T. L. 1965. Eighteenth-century attempts to resolve the vis viva controversy. Isis 56: 28I-97.

Hanov, M. Chr. I762. Philosophia naturalis, sive physica dogmatica, vol. I. Halle.

Hermann, J. I716. Phoronomia: sive, de viribus et motibus corporum. Amsterdam. 
Huygens, Chr. I897. Oeuvres complètes. Ed Société Hollandaise des Sciences, vol. VII. The Hague.

Iltis, C. (1970). D'Alembert and the vis viva controversy. Studies in History and Philosophy of Science A, I: 135-44.

Jacquier, Fr. 1785. Institutiones philosophicae, vol. 4. Venice.

Jalobeanu, D. 20I I. The Cartesians of the Royal Society. The Debate over Collisions and the Nature of Body (I668-I670). In Jalobeanu \& Anstey 20I I, I03-29.

Jalobeanu, D. and Anstey, P., eds. 20II. Vanishing matter and the laws of motion. Routledge.

Kant, I. I9I 2. Neuer Lehrbegriff der Bewegung und Ruhe. Kant's Gesammelte Schriften, ed. Berlin Academy of Sciences, vol, II, I3-26. Berlin: Georg Reimer.

Keill, J. I720. An introduction to natural philosoph. London: H.W.

Laudan, L. L. I968. The vis viva controversy, a post-mortem. Isis, 59: I30-43.

Lemonnier, P. I750 Cursus philosophicus, vol. 3. Paris.

MacLaurin, C. I728. Démonstration des loix du choc des Corps. In Recueil des pièces qui ont remporté les prix de l'Académie des Sciences. Paris.

Maupertuis, P.L.M. I734. Discourse on the Shapes of the Heavenly Bodies, translated in J. Keill, An Examination of Dr. Burnet's Theory of the Earth. London.

Meier, G. Fr. I765. Metaphysik, ed. II, vol. 2. Halle.

Murray, G., Harper, W., and Wilson C. 20II. Huygens, Wren, Wallis, and Newton on Rules of Impact and Reflection. In Jalobeanu and Anstey 201 I, I53-I94.

Musschenbroek, P. van. I744. The Elements of Natural Philosophy. Trans. J. Colson. London.

Newton, I. 1999. The Principia: Mathematical Principles of Natural Philosophy. Trans. I. B. Cohen and A. Whitman. Berkeley: University of California Press.

Oldenburg, H. I969. The Correspondence of Henry Oldenbourg, vol. VI, eds. A.R. Hall and M.B. Hall. Madison: University of Wisconsin Press.

Papineau, D. 1977. The vis viva controversy: do meanings matter? Studies in History and Philosophy of Science A. 8. II I-I 42.

Pemberton, H. I728. A view of Isaac Newton's philosophy. Dublin.

Prony, G.F.M.R de. [I799]. Mécanique philosophique; ou, Analyse raisonnée des diverses parties de la science de l'équilibre et du mouvement. Paris: Imprimerie de la République, An VIII. 
Pulte, H. I993. Die Newton-Rezeption in der rationalen Mechanik des I8. Jahrhunderts. Beiträge zur Geschichte von Technik und technischer Bildung 7, 33-59. Leipzig: Hochschule für Technik, Wirtschaft und Kultur.

Reichenberger, A. 20I2. Leibniz's Quantity of Force: A 'Heresy'? Émilie du Châtelet's Institutions in the context of the Vis Viva controversy. In Emilie du Châtelet between Leibniz and Newton. Ed. R. Hagengruber. Springer. I57-7I.

Robinet, A. 201 2. Malebranche et Leibniz: relations personnelles. Paris: Vrin-Reprise.

's Gravesande, W. J. I720. Mathematical elements of physicks, prov'd by experiments: being an introduction to Sir Isaac Newton's philosophy, Book I (translated into English by John Keill from the I 720 Latin edition).

Schmaltz, T. M. 2008. Descartes on Causation. Oxford University Press, New York.

Scott, W. L. I970. The Conflict between Atomism and Conservation Theory, I644 to I860. London: MacDonald.

Shank, J. B. 2008. The Newton Wars. Chicago University Press.

Smith, G. E. 2006. The vis viva dispute: A controversy at the dawn of dynamics. Physics Today 59: 3I.

Stan, M. 2009. Kant's early theory of motion. The Leibniz Review I9: 29-60.

Stan, M. 2015. Kant and the object of determinate experience. Philosophers' Imprint I5.

Terrall, M. 2004. Vis viva revisited. History of science 42: 189-209.

Wilson, M. 2018. Physics Avoidance. Oxford University Press.

Wilson, M. forthcoming. Newton at the Billiard Table. The Oxford Handbook of Newton, eds. Chr. Smeenk and E. Schliesser. Oxford University Press.

Wolff, Chr. I73I. Cosmologia generalis. Frankfurt and Leipzig. 